\title{
Dairy vs. beef production - expert views on welfare
}

${ }^{1}$ Behavioural Ecology Group, Section for Ecology \& Evolution, Department of Biology, University of Copenhagen, 2100 Copenhagen, Denmark.

${ }^{2}$ Section of Animal Welfare and Disease Control, Department of Veterinary and Animal

${ }^{3}$ Wageningen Livestock Research, Wageningen University and Research, Wageningen, The 3 Netherlands.

${ }^{4}$ Royal Veterinary College, Hatfield, United Kingdom.

${ }^{5}$ Professor Emeritus at the University of Bristol and Former Head of the Bristol Vet School, United Kingdom.

${ }^{6}$ Animal Husbandry \& Ethology, Albrecht Daniel Thaer-Institute of Agricultural and Horticultural Sciences, Humboldt-University of Berlin, Germany. 
Consumers' views and concerns about the welfare of farm animals may play an important role in their decision to consume dairy, meat and/or plants as their primary protein source. As animals are killed prematurely in both dairy and beef industries, it is important to quantify and compare welfare compromise in these two sectors before the point of death. Seventy world-leading bovine welfare experts based in 23 countries, were asked to evaluate the likelihood of a bovine to experience 12 states of potential welfare concern, inspired by the Welfare Quality® protocol. The evaluation focused on the most common beef and dairy production systems in the experts' country, and was carried out separately for dairy/beef calves raised for red-meat, dairy/beef calves raised for veal, dairy/beef calves raised as replacement, and for dairy/beef cows. The results show experts rated the overall likelihood of a negative welfare state (i.e. welfare risk) to be higher in animals from dairy herds than from beef herds, for all animal categories, regardless of whether they were used to produce milk, red-meat or veal. These findings suggest that consuming food products derived from common dairy production systems (dairy or meat), may be more harmful to the welfare of animals than consuming products derived from common beef production systems (i.e. from animals solely raised for their meat). Raising awareness about the linkage between dairy and meat production, and the toll of milk production on the welfare state of animals in the dairy industry, may encourage a more sustainable and responsible food consumption. 
Abstaining from consuming meat, but not dairy products, is regarded by many to be a sign of compassion towards animals [1,2]. Vegans go a step further and reject the consumption of any animal-based product, but few, if any, advocate abstention from dairy while continuing to consume meat. The extent to which an independent analysis of animal welfare aligns with such consumer choices has not previously been examined. Importantly, there are substantial reasons to predict a discrepancy, particularly when considering the role of the dairy industry in producing meat (Figure 1A), and the higher degree of intervention in the lives of animals that are used "for more than their meat" (i.e. intervention associated with daily milking of the dams, and the consequent management of their calves). Here, we obtained an independent assessment of the likelihood that dairy cattle and beef cattle would experience negative welfare, by surveying a panel of leading cattle welfare experts, each focusing on the most common beef and dairy production systems in their country of expertise. The comparison was carried out between dairy and beef calves when raised directly for their meat (i.e. dairy and beef calves raised for red-meat and for veal, consisting mostly of male calves), and between dairy and beef cows raised for producing calves/milk.

4

Expert assessments can help to characterise uncertainty and fill data gaps where traditional scientific research is not possible or data are not yet accessible or available [3]. Such assessments have been widely used to review impacts of housing, management or other anthropogenic challenges to domestic (e.g. [4] cattle; [5] broilers and [6] canine and felines) and wild animals (e.g. [7]), using frameworks such as the Five Domains (e.g. [7,8]), and more recently, in relation 
to the United Nations Sustainable Development Goals $[9,10]$. The European Food and Safety

\section{0} Authority (EFSA) commonly uses expert opinion to inform debates around welfare topics, such as the use of perches for laying hens [11], and for assessing welfare risks, such as those that relate to the farming of sheep for wool, meat and milk production [12].

In the next section, we compare experts' assessment of the overall likelihood that bovines will experience a negative welfare state when raised in the most common housing systems in the dairy and beef sectors, with a focus on Europe and North America. We predicted that the higher degree of intervention in the lives of dairy cattle, which stems from the fact that they are used for "more than their meat" (i.e. harvesting of milk, affecting their management and the management of their calves), would result in dairy cattle being rated by experts as being at a higher welfare risk than beef cattle.

\section{Methods}

An approval to conduct this study was granted by the Research Ethics Committee for SCIENCE and HEALTH of the university of Copenhagen, ref: SUSTA, case: 504-0272/21-5000. Approval and registration of processing of personal data in the project was provided by the legal department of the university of Copenhagen, ref PWI, case: 514-0273/21 - 5000. 


\section{Data Collection}

Overall, 130 cattle welfare experts were invited to participate in our survey. based on their 1. Number of publications on the topic of bovine welfare (peer reviewed research manuscripts and review articles) that appear in the Web of Science data base, when using the following key words: "Welfare" + "bovine"/"cattle"/"dairy cow"/"beef cow") (selected experts were those with the highest number of publications) and 2. H-index (minimum of 10). In addition, we invited further researchers that were recommended to us by the selected experts. Overall, 83 experts agreed to participate in the survey, out of which 13 were omitted from the final analysis for the following reasons: 10 experts did not complete the survey, 2 experts felt that they could not provide accurate assessments, and one expert felt that his degree of expertise was not sufficient. Data were collected through an online survey built in Qualtrics (Qualtrics XM Platform ${ }^{\mathrm{TM}}$, Provo, Utah, USA), between October and December 2020.

The survey included four parts: 1 . Consent including a short description of the aim of the experiment "to compare the welfare of cattle across food production systems". 2. General instructions. 3. Characterization of the common production systems, likelihood ratings and confidence ratings. 4. Characterization of experts (as summarized in S1 Table).

\section{Characterization of the common production systems. Before providing likelihood ratings, the} experts were asked to describe the most common beef and dairy production systems in their country of expertise. The characterization applied to each animal category separately, using 3-5 fixed criteria (S1 Fig.; S3 Table), to which the experts could answer: "yes", "partial/part of the time", "no", or "I don't know". 
117 Likelihood rating. The experts were asked to rate the likelihood of 12 statements on a scale of 1 (very low) to 7 (very high), and to notice that the statements were built in such a way that the higher the likelihood ratings are, the higher is the welfare-risk for the animal (for illustration see S1 Fig., for the exact questions and ratings see Table 1). The 12 short welfare statements that were inspired by the Welfare Quality protocol [13], a well-established protocol for assessing bovine welfare. The statements addressed the following core areas of potential welfare concern: 1. inadequate diet, 2. inadequate water supply, 3. thermal discomfort, 4. resting discomfort, 5. injuries, 6. disease, 7. pain resulting from management/handling/surgical procedures, 8. inability to move freely, 9. inability to perform social behavior, 10. inability to perform other normal behaviors, 11. experiencing negative affective states, and 12. lack of experiencing positive affective states (for the order of presentation, see Table 1). Since management practices were expected to vary between countries for both beef and dairy sectors (for red-meat, veal, replacement, and cows), animal categories were defined as follows: For red meat calves and veal, the evaluation period was from birth to slaughter (or up to 18 months of age). For replacement calves it was from birth to first calving. For cows, it was from first calving to slaughter. In all cases, the evaluation did not include transportation to slaughter or the process of slaughter itself. To avoid order effects (where rating one animal origin first (e.g. beef) would affect the rating of the other (e.g. dairy), we used 4 complementary versions of the survey. In all four versions, the presentation of animal category was fixed: Red-meat, replacement calves, cows and veal. However, the order of presenting the animal origin (beef/dairy) was counter balanced (left/right*text colour blue/orange). In each of the four versions, the text colour and order of presentation in Fig. 1A was matched accordingly. 
Confidence rating. The experts were asked to state their level of confidence in their likelihood ratings on a 5 point scale $(1$ star $=$ low confidence to 5 stars $=$ high confidence $)$. Confidence ratings were reported separately for each of the animal origins in the four animal categories (S2 Fig., and Table 1).

\section{Data processing}

We omitted all answers from respondents that had provided an incomplete set of answers for a given combination of animal origin and category. This left the answers of 70 experts (out of 83). In total $1,3,34,25$, and 7 experts gave complete answers for $3,4,6,7$, and 8 of the 8 possible combinations of origin and animal category, respectively. ratings were reported on a seven point Likert-scale. A Likert-scale has a fixed lower and upper limit and is therefore comparable to a proportion. Accordingly, it can be expected that a logittransformation will lead to normally distributed data points. Two experts indicated an interval for the Likert-scale ranging one scale point instead of a single number. In these cases, we used the mid-point of the interval (i.e. the average of the two indicated scale points), which resulted in non-integer scale points at half the original points. Consequently, the resulting Likert-scale had 13 scale points: the integers from 1 to 7 and all the midpoints between the integers $(1.5,2.5, \ldots)$. In a next step, we re-scaled the 13-point Likert scale to a score on a scale from 0 to 1 . We did this in a way that kept the steps between the points of the Likert-scale equal and shifted the minimum and maximum scale points half the distance between the points away from 0 and 1 : 
proportion $=4 /(2 * 13)$ Likert-scale $-3 /(2 * 13)($ S3 Fig. $)$. We then logit transformed the numbers of this 0-1 scale ("normalised values").

The likelihood ratings were dependent on expert who rated the likelihood of the 12 welfare statements once for each of the two origins and for the four animal categories. To account for this dependency, we calculated the residuals of a mixed model with expert ID as the sole random effect and the intercept as the fixed effect using the 12 normalised values as an outcome variable each. In doing so, we adjusted the average likelihood rating of each expert to the overall average of all experts. Quantile-quantile plots of these 12 sets of residuals showed that they were very close to normally distributed. They thus provided the data for running a principal component analysis (PCA).

\section{Statistical analysis}

For statistical evaluations R V 4.0.3 was used [14]. A PCA based on the correlation matrix (function princomp; base R) was run for each set of variables that reflected information on the most common housing systems of the different animal categories in the countries for which experts made an assessment. These PCAs were based on raw scorings of the answers (no= 1 , partly $=2$, yes $=3$ ) and responses of experts with missing answers were omitted. Veal from beef origin was also omitted because information for this category was given by less than $15 \%$ of the experts $(n=10$ of 70$)$.

The residuals of normalised values for the 12 welfare statements (see above) were subjected also to a PCA. The first principle component of this PCA, which explained $50.3 \%$ of the total 
variance, was then used as the outcome variable in a linear mixed-effects model (function blmer, package blme [15], which is based on lme 4 [16]). The fixed effects in the model were the origin of the animals (two-level factor: dairy versus beef), the animal category (four-level factor: calves raised for red-meat, calves raised for replacement, cows, and veal calves) and their interaction. To be able to interpret average main effects even in the presence of interactions, sum-contrasts were used for the fixed effects. The random effect was animal category nested in expert and the confidence ratings were used as weights. Residuals were checked graphically, using a QQ-plot of the raw residuals and the standard plots using simulated residuals in package DHARMa [17]. The model with the confidence weights showed a slight s-shape in the QQ-plot of DHARMa but the estimated effects were almost unchanged in comparison with the model without weights. We therefore report the model with weights. We calculated p-values by comparing the maximum model with one model each that omitted one of the fixed effects using a parametric bootstrap which fitted the raw data well (Fig. 1).

Overall 70 cattle welfare experts participated in the survey. The experts, who had a median

\section{Results}

experience of at least 15 years, were recruited from Europe (36), North America (17), South 
America (8), Australia (5), and other regions of the world (4). Additional characteristics of the experts can be found in S1 Table.

Experts' likelihood and confidence ratings for each of the 12 statements are shown in Table 1. The overall likelihood to experience a negative welfare state (i.e. welfare risk) was assessed by 212 the experts as higher in animals from dairy in comparison to beef, for all animal categories 213 (origin: $\mathrm{p}=0.001$, interaction: $\mathrm{p}=0.28$; Figure $1 \mathrm{~B}$ ). The overall welfare risk increased from 214 calves raised for replacement and cows, to calves raised for red-meat and to veal calves ( $p=$ 215 0.001; Figure 1B). These results indicate that, regardless of the production goal (calves raised for 216 red-meat, calves raised for veal, calves raised as replacement, and cows), animals born in dairy 217 herds were considered to experience worse welfare than animals born in beef herds. 
A

222

$$
\text { Beef industry }
$$
(beef herd origin)
Dairy industry (dairy herd origin)

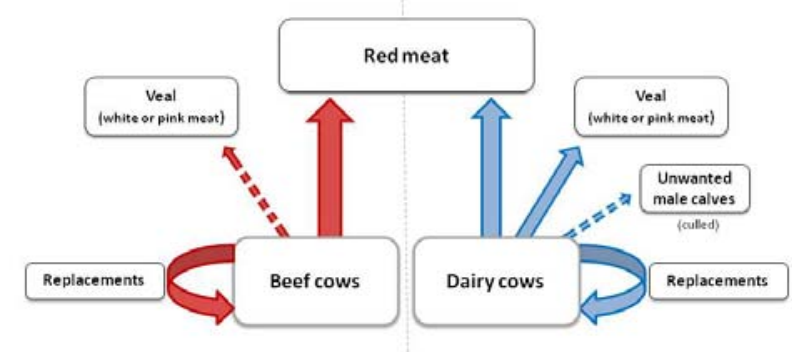

B
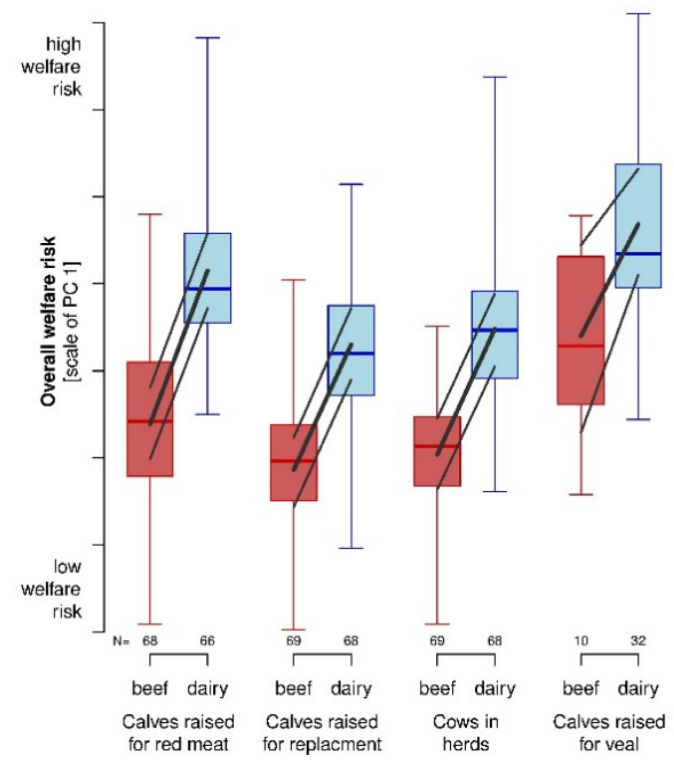

Figure 1. (A) Diagram showing the origin (dairy/beef herd) and production goals, i.e. the general flow of calves from dairy herds and beef herds to red-meat, veal and cow replacements (inspired by EFSA Panel on Animal Health and Welfare [19]. Dashed arrows reflect production routes that are not common to all farms. (B) First principal component reflecting the overall welfare risk (likelihood of 12 welfare concerns, see text) as assessed by the experts as a function of the different origins and animal production goals. N: Number of experts that reported an assessment on all 12 areas of welfare concern. Boxplots: show minimum, lower quartile, median, upper quartile and maximum values. Black lines: model estimates with $95 \%$ upper and lower confidence intervals. 
Table 1 - likelihood - likelihood and confidence ratings for each of the 12 statements. Raw data. Mean (STD) and median [min $\max ]$.

\begin{tabular}{|c|c|c|c|c|c|c|c|c|c|}
\hline \multirow{2}{*}{$\begin{array}{c}\text { Animal category } \\
\text { Animal origin (herd) }\end{array}$} & \multicolumn{2}{|c|}{ Red-meat } & \multicolumn{2}{|c|}{ Replacement Calves } & \multicolumn{2}{|c|}{ Cows } & \multicolumn{2}{|c|}{ Veal } & \multirow{2}{*}{ 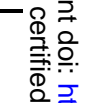 } \\
\hline & Beef & Dairy & Beef & Dairy & Beef & Dairy & Beef & Dairy & \\
\hline \multirow{2}{*}{$\begin{array}{l}\text { Q1: Receive inappropriate/inadequate diet (e.g. quantity of feed, number of } \\
\text { feeding bouts, quality of feed, digestibility etc.). }\end{array}$} & $2.4(1.4)$ & $4.2(1.9)$ & $2.2(1.4)$ & $3.4(1.7)$ & $2.8(1.3)$ & $2.7(1.6)$ & $3.5(2.0)$ & $4.7(1.9)$ & \\
\hline & $2[1-7]$ & $4[1-7]$ & $2[1-7]$ & 3 [1-7] & $3[1-7]$ & $2[1-7]$ & $4[1-7]$ & $5[1-7]$ & \\
\hline \multirow{2}{*}{$\begin{array}{l}\text { Q2: Have inadequate water supply (e.g. quantity, quality, accessibility, high } \\
\text { competition over access to water). }\end{array}$} & $2.2(1.3)$ & $2.6(1.5)$ & $2.0(1.2)$ & $2.4(1.5)$ & $2.4(1.3)$ & $2.3(1.4)$ & $3.3(2.3)$ & $3.4(1.8)$ & \\
\hline & $2[1-7]$ & $2[1-7]$ & $2[1-7]$ & $2[1-7]$ & $2[1-7]$ & $2[1-7]$ & $3[1-7]$ & $4[1-7]$ & \\
\hline \multirow{2}{*}{$\begin{array}{l}\text { Q3: Experience discomfort when resting (e.g. when lying down, standing up } \\
\text { etc.). }\end{array}$} & $2.4(1.6)$ & $3.8(1.7)$ & $2.1(1.3)$ & $3.1(1.5)$ & $2.2(1.3)$ & $3.7(1.5)$ & $3.6(2.3)$ & $4.5(1.6)$ & \\
\hline & $2[1-7]$ & 4 [1-7] & $2[1-7]$ & 3 [1-7] & $2[1-6]$ & 4 [1-7] & 4 [1-7] & $5[1-7]$ & \\
\hline \multirow{2}{*}{$\begin{array}{l}\text { Q4: Experience thermal discomfort (i.e. being too warm (e.g. heat load) or } \\
\text { too cold). }\end{array}$} & $3.3(1.4)$ & $3.3(1.6)$ & $3.0(1.4)$ & $3.1(1.4)$ & $3.2(1.4)$ & $3.3(1.5)$ & $3.7(1.6)$ & $3.9(1.5)$ ํㅡㅁ & \\
\hline & 3 [1-7] & 3 [1-7] & 3 [1-6] & 3 [1-6] & 3 [1-6] & 3 [1-7] & 4 [2-6] & $4[1-6]$ & \\
\hline \multirow{2}{*}{$\begin{array}{l}\text { Q5: Experience restricted movement (e.g. limited ability to move around } \\
\text { freely, e.g. being tied, kept in high stocking density). }\end{array}$} & $2.4(1.6)$ & $4.3(1.7)$ & $2.0(1.3)$ & $3.6(1.5)$ & $2.0(1.2)$ & $3.6(1.7)$ & $3.5(2.1)$ & $5.0(1.5)$ & \\
\hline & $2[1-7]$ & 4 [1-7] & $2[1-7]$ & $3[1-7]$ & $2[1-7]$ & $4[1-7]$ & 4 [1-7] & $5[2-7]$ & $\frac{\overrightarrow{0}}{\text { के }}$ \\
\hline \multirow[t]{2}{*}{ Q6: Suffer from injuries (e.g. lameness, skin lesions etc.). } & $2.6(1.4)$ & $3.4(1.5)$ & $2.2(1.1)$ & $2.9(1.3)$ & $2.7(1.3)$ & $4.7(1.4)$ & $3.0(1.8)$ & $3.9(1.5)$ d & \\
\hline & $2[1-7]$ & $3[1-7]$ & $2[1-7]$ & $3[1-7]$ & $3[1-7]$ & $5[2-7]$ & $3[1-6]$ & $4[1-7] \frac{1}{2}$ & \\
\hline \multirow[t]{2}{*}{ Q7: Suffer from disease } & $3.1(1.4)$ & $4.2(1.6)$ & $2.6(1.1)$ & $3.6(1.4)$ & $2.7(1.1)$ & $4.2(1.6)$ & $3.8(1.8)$ & $5.0(1.4) \uparrow$ & \\
\hline & $3[1-6]$ & $4[1-7]$ & $2[1-7]$ & 4 [1-7] & 3 [1-6] & 4 [1-7] & $4[2-6]$ & $5[1-7] \cong$ & \\
\hline \multirow{2}{*}{$\begin{array}{l}\text { Q8: Suffer from pain induced by management, handling, or surgical } \\
\text { procedures }\end{array}$} & $4.1(2.0)$ & $4.4(1.8)$ & $3.2(1.8)$ & $4.1(1.9)$ & $2.7(1.4)$ & $3.4(1.6)$ & $3.5(1.8)$ & $3.8(1.7)$ & \\
\hline & 4 [1-7] & 4 [1-7] & 3 [1-7] & 4 [1-7] & $2[1-7]$ & 3 [1-7] & 3 [2-7] & $3[1-7]$ & \\
\hline \multirow{2}{*}{$\begin{array}{l}\text { Q9: Have limited opportunities to express normal, non-harmful, social } \\
\text { behaviors (e.g. limited allo-grooming, limited social play etc.). }\end{array}$} & $2.2(1.5)$ & $4.0(1.9)$ & $2.0(1.2)$ & $3.4(1.7)$ & $1.9(1.1)$ & $3.2(1.4)$ & $3.8(2.2)$ & $5.0(1.5)$ & \\
\hline & $2[1-7]$ & 4 [1-7] & $2[1-7]$ & 3 [1-7] & $2[1-6]$ & 3 [1-6] & 4 [1-7] & $5[2-7]$ & \\
\hline \multirow{2}{*}{$\begin{array}{l}\text { Q10: Have limited opportunities to express other normal behaviors (i.e. } \\
\text { limited/restricted from opportunity to forage/graze). }\end{array}$} & $2.7(1.7)$ & $4.9(1.7)$ & $1.9(1.2)$ & $3.9(1.7)$ & $1.8(1.2)$ & $3.9(1.5)$ & $4.1(2.4)$ & $6.0(1.3)$ & \\
\hline & 2 [1-7] & $6[1-7]$ & $2[1-6]$ & 4 [1-7] & $2[1-7]$ & 4 [1-7] & 4 [1-7] & $6[2-7]$ & \\
\hline \multirow{2}{*}{$\begin{array}{l}\text { Q11: Experience negative affective states (e.g. fear, distress, frustration or } \\
\text { apathy; due to negative human-animal relationships, husbandry / } \\
\text { management or the environment in which the animal is kept). }\end{array}$} & $3.0(1.5)$ & $4.3(1.7)$ & $2.6(1.2)$ & $3.4(1.5)$ & $2.5(1.3)$ & $3.6(1.6)$ & $4.2(2.3)$ & $4.9(1.7)$ & \\
\hline & 3 [1-7] & 4 [1-7] & 2 [1-7] & 3 [1-7] & 2 [1-7] & 4 [1-7] & 4 [1-7] & 5 [1-7] & \\
\hline \multirow{2}{*}{$\begin{array}{l}\text { Q12: Have limited opportunities to experience positive emotions (e.g. } \\
\text { limited opportunities to engage in rewarding activities). }\end{array}$} & $2.7(1.6)$ & $4.5(1.6)$ & $2.2(1.3)$ & $3.6(1.5)$ & $2.2(1.2)$ & $3.6(1.4)$ & $3.6(2.3)$ & $5.1(1.7)$ & \\
\hline & 2 [1-7] & 5 [1-7] & 2 [1-6] & 4 [1-7] & 2 [1-6] & 4 [1-6] & 3 [1-7] & 5 [1-7] & \\
\hline \multirow{2}{*}{ Confidence in ratings } & $3.9(0.9)$ & $3.8(0.8)$ & $3.8(1.1)$ & $4.1(0.8)$ & $4.0(1.0)$ & $4.3(0.7)$ & $3.9(1.0)$ & $3.8(1.0)$ & \\
\hline & $4[1-5]$ & $4[2-5]$ & $4[1-5]$ & $4[2-5]$ & $4[1-5]$ & $4[2-5]$ & $4[2-5]$ & $4[1-5]$ & \\
\hline
\end{tabular}




\section{Discussion}

"Harvesting" milk from bovines has a long tradition ("secondary products revolution"[20]), and it

For this reason, it is important to critically reflect on the welfare impact of this practice. Our expert survey showed that bovines raised in main current food production systems are rated as more likely to experience negative welfare conditions if raised in dairy systems (regardless of whether they are used for their milk or meat) than in beef systems (i.e. when raised solely for their meat). This result may be surprising in light of societal perceptions regarding ethical food choices (vegetarianism [1,2]) and deserves further consideration to identify candidate underpinning reasons.

Our assessment protocol allowed us to cover a wide range of production methods (for the result of the PCAs for the information on the housing systems, see S5 Fig.) and to assess experts ratings of the overall welfare risk of animals raised in these conditions during the majority of their life-time (for the

257 'raw' ratings of experts, for each of the 12 areas of welfare concern, see Table 1). Nevertheless, it did not allow us to disentangle which of the welfare risks mentioned above formed the basis for the experts' ratings. In addition, we emphasize that the results do not necessarily mean that animals born

260 in dairy herds are, at any given point of time and in every type of system, worse off than animals born

261 in beef herds. For example, after spending several months on pasture with their dam, the welfare of 262 beef suckler calves is expected to be substantially reduced once they are moved to feedlots, 263 potentially below the levels experienced by many dairy calves raised for red-meat (see Figure 1 [35]; 264 for a review of the factors affecting cattle welfare in feedlots see [36,37]; for cattle preferences to being on pasture over the feedlot area see [38]). It would be interesting to explore whether experts 
would consider that improvements to the welfare of bovines in the dairy industry e.g. by keeping dairy calves with their dams [39], free access to pasture [40] and the use of pain relief, e.g. in case of lameness [41] and during practices such as dehorning [42] would be sufficient to balance the overall welfare risk for animals raised in the two production systems. The answer cannot be predicted in advance because, for example, if such measures were similarly applied to bovines in the beef industry, then they may retain their perceived higher welfare status.

One possible reason why experts rated dairy systems as more harmful to welfare may be because harvesting milk from bovines involves a higher (negative) intervention in their lives compared to raising them solely for their meat. Raising bovines for their meat involves feeding and slaughtering them. Dairy cows, are also bred for their milk, which is then collected 1-3 times per day, often for 305 days or more per lactation [22,23], and this has implications for how these animals are raised and managed. Long term genetic selection for high milk yield in dairy cows has been recognized as a major factor causing poor welfare, in particular health problems, such as lameness, mastitis, reproductive disorders and metabolic disorders [24]. Adoption of high yielding breeds such as the Holstein-Friesian without consideration for the animals' natural ability to cope with diseases [24] and thermal challenges typical of extreme climates may lead to additional welfare compromises [25,26]. Common housing and husbandry procedures characterizing the management of dairy cattle increase the welfare risks further. For example, dairy calves, in contrast to beef calves, are commonly separated from their dam a few hours after birth to allow the collection of milk from their mothers [24,27]. Upon separation, they are often kept in social isolation for several weeks (i.e. limited or no physical contact with their dam or conspecifics), a management practice that originated from the desire to reduce horizontal transmission of disease between calves, yet has been repeatedly shown to 
inflict behavioural and developmental harm [28]. The social and nutritional restrictions following the separation from the dam have been implicated as key animal welfare issues in commercially raised dairy calves [29], with the former being associated with cognitive and social impairments effecting the welfare of the animals also at a later age. Male dairy calves are often transported to a different farm at a young age, increasing their welfare risk further [30]. Later in life, dairy calves raised to produce milk ("replacement dairy calves") are commonly housed indoors for part of the year (i.e. winter) or continuously (i.e. zero grazing system), in free or tie-stall systems [31]. Keeping dairy cattle indoors is associated with numerous behavioural restrictions [32,33] and health risks, such as higher incidence of lameness [34], and increased risk for claw or foot problems, teat trampling, mastitis, metritis, dystocia, ketosis, retained placenta, and some bacterial infections compared to systems that allow cattle access outdoors [24]. Since dairy cattle are commonly raised indoors for at least part of the year, and since their management involves a high degree of intervention as described above (in the first weeks of life following the separation from their dam, and throughout the lactating periods, when milked by partially/fully automated milking systems), their management is expected to involve a higher risk to their welfare compared to beef cattle. A future study could specifically explore which of these factors most influence expert rankings of welfare.

Our study focused on the welfare risks of dairy and beef cattle, before being slaughtered/culled. It is important to note however, that the period during which the animals are subjected to these risks varies between production goals, production stages and the management goals of the farm (Figure 1A). Veal calves (from both dairy and beef herd origin) are usually slaughtered at the age of 6-11 months, depending on whether they are used to produce white or rose veal (but see culling of 'surplus'/bobby dairy calves within the first days of life [43]). Calves raised for red-meat (from both dairy and beef 
312 herds) are usually slaughtered at 12-36 months, while replacement cows, which are used in both types

313 of systems to produce both milk and calves, will commonly be slaughtered at an earlier age in dairy

314 herds than beef herds. In the US, for example, dairy cows are slaughtered at about 5 years of age

315 (after 2.5-3 lactations), while beef cows are slaughtered at 7-12 years of age [44]. The production of

316 milk, like beef production, involves killing of animals, yet in many cases, this happens at a younger

317 age in the dairy industry. Factoring the intensity of welfare compromise in the life time expectancy

318 (i.e. duration) of these animals, could deepen our understanding of the overall welfare impact.

319 However, it is beyond the scope of this paper. Here and throughout the manuscript, we avoid making

320 any ethical claims about sanctity of life. Also, we do not aim to value the amount of suffering per

321 animal in relation to the amount of animal protein (or calorie [45]). Our aim was more

322 straightforward, to assess, based on expert opinion, the welfare of animals born to common dairy and 323 beef herds, until slaughtered/culled.

At a time of rising public concern for the welfare of animals [46] and awareness of the impact of our diets on the environment [47], it is important that research priorities and dietary choices are aligned with the areas where welfare problems are most apparent. We call for further comparisons of bovine welfare in less common dairy and beef production systems that were not covered here (e.g. organic systems, dam rearing systems, where dairy calves are kept together with their dam), preferably using animal-based welfare assessment on farm. It would also be valuable to obtain representative overview

331 of the prevalence of these different systems across countries. In addition, we encourage a similar 332 expert comparison of other farm species that, like dairy cows, are used for "more than their meat"; 333 e.g. laying hens could be compared with broilers to see if the findings from this study apply in other 334 areas of animal agriculture. 


\section{Conclusion}

339 Cattle welfare experts rated dairy cattle as significantly/substantially more likely to experience 340 negative welfare than beef cattle in the most common housing systems selected by the experts. The

341 underpinning reasons for these evaluations were not explored with experts but are proposed to enable 342 testable predictions for future research. Exploring the alignment between consumer choices and 343 independent evaluations of animal welfare may encourage a more sustainable and responsible food 344 production and consumption.

\section{References and Notes:}

349 1. Fox N, Ward K. Health, ethics and environment: A qualitative study of vegetarian motivations.

$350 \quad$ Appetite. 2008; 50: 422-429.

352 2. Corrin T, Papadopoulos A. Understanding the attitudes and perceptions of vegetarian and plant-

353 based diets to shape future health promotion programs. Appetite. $2017 ; 109: 40-47$. 
3. EFSA Panel on Animal Health and Welfare (AHAW). Guidance on risk assessment for animal welfare. EFSA Journal. 2012; 10: 2513. the welfare assessment of dairy cows: Elicitation of expert opinion. Preventive Veterinary Medicine. $3612018 ; 150,8-18$.

5. Bracke MB, Koene P, Estevez I, Butterworth A, de Jong IC. Broiler welfare trade-off: A semiquantitative welfare assessment for optimised welfare improvement based on an expert survey. PloS one. $2019 ; 14, \mathrm{e} 0222955$. practicing veterinarians to identify and explore key factors thought to influence canine and feline welfare in relation to veterinary care. Animal Welfare. 2016; 25: 125-134. 
Yeates J, Jones B. Using the five domains model to assess the adverse impacts of husbandry, veterinary, and equitation interventions on horse welfare. Animals. 2018; 8: 41

9. Nations U. Transforming our world: The 2030 agenda for sustainable development. New York: United Nations, Department of Economic and Social Affairs. 2015 Oct 21 [Cited 2021 November 23].

10. Keeling L, Tunón H, Olmos Antillón G, Berg C, Jones M, Stuardo L, Swanson J, Wallenbeck A,

Winckler C, Blokhuis H. Animal welfare and the united nations sustainable development goals. aspects of the use of perches for laying hens. EFSA Journal. 2015; 13: 4131.

13. Welfare Quality® 2009. Assessment protocol for cattle. Welfare Quality® Consortium, Lelystad, Netherlands. Available from: http://www.welfarequalitynetwork.net/en-us/reports/assessmentprotocols 
401 15. Chung Y, Rabe-Hesketh S, Dorie V, Gelman A, Liu J. A nondegenerate penalized likelihood

402 estimator for variance parameters in multilevel models. Psychometrika. 2013; 78: 685-709.

403

404

16. Bates D. Fitting Linear Mixed-Effects Models Using lme4. Journal of Statistical Software. 2015;

405 67: 1-48.

406

407 17. Hartig F. DHARMa: Residual Diagnostics for Hierarchical (Multi-Level / Mixed) Regression

408 Models. 2020. R package version 0.3.3.0. Retrieved from: https://CRAN.R-

409 project.org/package=DHARMa

410

411 18. Halekoh U, Højsgaard S. A kenward-roger approximation and parametric bootstrap methods for 412 tests in linear mixed models-the R package pbkrtest. Journal of Statistical Software. 2014; 59: 1-30.

19. EFSA Panel on Animal Health and Welfare (AHAW) 2012. Scientific Opinion on the welfare of

415 cattle kept for beef production and the welfare in intensive calf farming systems. EFSA Journal 10: 4162669.

417

418 20. Sherratt A. The secondary exploitation of animals in the Old World. World archaeology. 1983; 15:

$41990-104$.

420

421 21. OECD-FAO Agricultural forecast 2020-2029 (OECD Publishing, Paris, 2020). Retrieved from: 422 https://www.fao.org/documents/card/en/c/ca8861en [Cited 2021 November 23]. 
424 22. Dematawewa CMB, Pearson RE, VanRaden PM. Modeling extended lactations of Holsteins.

425 Journal of Dairy Science. 2007; 90: 3924-3936.

426

23. Sehested J, Gaillard C, Lehmann JO, Maciel GM, Vestergaard M, Weisbjerg MR, Mogensen L,

Larsen LB, Poulsen NA, Kristensen T. Review: extended lactation in dairy cattle. Animal. 2019; 13:

24. Algers B, Blokhuis HJ, Botner A, Broom DM, Costa P, Domingo M, Greiner M, Hartung J,

Journal of Dairy Science. 2013; 96: 5405-5425. 
447 28. Costa JHC, Von Keyserlingk MAG, Weary DM. Invited review: Effects of group housing of

448 dairy calves on behavior, cognition, performance, and health. Journal of Dairy Science. 2016; 99:

$449 \quad 2453-2467$.

450

29. Costa JH, Cantor MC, Adderley NA, Neave HW. Key animal welfare issues in commercially raised dairy calves: social environment, nutrition, and painful procedures. Canadian Journal of Animal Science, 2019; 99: 649-660. 103: 11628-11635. welfare. Journal of Dairy Science. 2015; 98: 7426-7445. dairy cows and calves in indoor housing. Journal of Dairy Science. 2016; 99: 1695-1715. 
470 34. Haskell MJ. What to do with surplus dairy calves? Welfare, economic and ethical considerations.

471 Landbauforschung. 2020; 70: 45-48.

472

35. Bracke MBM, Edwards SA, Engel B, Buist WG, Algers B. Expert opinion as ‘validation’ of risk assessment applied to calf welfare. Acta Veterinaria Scandinavica. 2008; 50: 29. Available at

36. Tucker CB, Coetzee JF, Stookey JM, Thomson DU, Grandin T, Schwartzkopf-Genswein KS.

Research Reviews. 2015; 16: 107-124.

37. Salvin HE, Lees AM, Cafe LM, Colditz IG, Lee C. Welfare of beef cattle in Australian feedlots: 
40. Mee JF, Boyle LA. Assessing whether dairy cow welfare is "better" in pasture-based than in confinement-based management systems. New Zealand Veterinary Journal. 2020; 68: 168-177.

41. Whay HR, Webster AJF, Waterman-Pearson AE. Role of ketoprofen in the modulation of hyperalgesia associated with lameness in dairy cattle. Veterinary Record. 2005; 157: 729-733.

42. Stafford KJ, Mellor DJ. Addressing the pain associated with disbudding and dehorning in cattle. Applied Animal Behaviour Science. 2011; 135: 226-231.

43. Haskell MJ, Rennie LJ, Bowell VA, Bell MJ, Lawrence AB. Housing system, milk production, and zero-grazing effects on lameness and leg injury in dairy cows. Journal of Dairy Science. 2006; 89: 4259-4266.

44. Moreira, LC, Rosa GJM, Schaefer DM. Beef production from cull dairy cows: a review from culling to consumption. Journal of Animal Science. 2021; 99: 1-18.

45. Kolbe K. Why milk consumption is the bigger problem: Ethical implications and deaths per calorie created of milk compared to meat production. Journal of Agricultural and Environmental Ethics. 2018; 31: 467-481.

46. Miele M, Blokhuis H, Bennett R, Bock B. Changes in farming and in stakeholder concern for animal welfare. In Improving farm animal welfare (pp. 19-47). Wageningen Academic Publishers, Wageningen. 2013. 
515 47. Kearney J. Food consumption trends and drivers. Philosophical transactions of the royal society

516 B: biological sciences. 2010; 365: 2793-2807.

519 Author contributions:

520 RM, LG, MBMB and CJN designed research; RM performed research; LG and RM analyzed data;

521 RM, LG, MBMB, CJN and JAW wrote the paper.

\section{Competing interests:}

525 Authors declare no competing interests. All data are available in the main text or the Supplementary 526 Materials. 
bioRxiv preprint doi: https://doi.org/10.1101/2021.12.06.471462; this version posted January 20, 2022. The copyright holder for this preprint (which was not certified by peer review) is the author/funder, who has granted bioRxiv a license to display the preprint in perpetuity. It is made available under aCC-BY-ND 4.0 International license.

\section{Supporting information}

532 This PDF file includes:

534 Supplementary text.

535 S1-S5 Figures.

536 S1-S3 Tables. 


\section{Supplementary text}

\section{PCA, 12 animal welfare statements}

541 The PCA on the residuals of the normalised values of the 12 welfare statements resulted in a first

542 principal component (PC) that explained $50.3 \%$ of the overall variability, which was clearly more 543 than any other PC (S2 Table, S4 Fig.).

544 As all the original variables loaded positively on this first PC, it can be interpreted accordingly as the

545 overall welfare risk summarising all the 12 original welfare statements. The highest loads were

546 reached by the risk of restricted ability to express other normal behaviours, of restricted movement, of

547 restricted ability to express social behaviours, of discomfort when resting, of experiencing negative

548 affective states and of restricted experience of positive emotions ( 22 Table). The beef versus dairy

549 origin was well separated along this first PC (Fig. 1 in main text; S4 Fig.).

550 All additional PCs explained a much smaller proportion of the variance and were mostly difficult to

551 interpret. Due to their limited contribution to the overall variability in the data, no attempt was made

552 at their interpretation and they were not further considered for analyses.

\section{PCAs, information on the housing systems}

555 The analyses of the information on the housing systems showed that beef versus dairy origin can be

556 well separated along the first PC in all the animal categories (S3 Table, S5 Fig., a-d).

557 For the calves raised for red-meat, the housing systems could be described by two PCs, of which the 558 first was composed of access to pasture, access to dam and suckling from dam during the first months 559 of life and not being transported during the first 6 months of life ("extensitivity" which may be closely related to available space), whereas the second concerned being slaughtered before or after 18 
561 months of age (S3 Table). Beef and dairy systems seemed to differ mostly by the beef systems being

562 more extensive (S5a Fig.). For the calves raised for replacement, the results were very similar with

563 the exception that the transportation loaded on the second PC (S3 Table, S5b Fig.) and that, due to

564 their purpose, they were not slaughtered by default.

565 The housing of beef and dairy cows seemed to vary mostly in the extent that access to the outdoors

566 was provided (S3 Table, S5c Fig.). Here, beef cows seemed to have access to the outdoors more

567 commonly than dairy cows and dairy cows ran a higher risk of being culled early.

568 The housing of veal calves seemed to vary the most in respect to the type of flooring provided with

569 bedding material and access to pasture versus housing on slatted floors loading heavily on the first PC

570 (S3 Table, S5d Fig.). The second PC was a contrast of the provision of (additional) solid feed and

571 being slaughtered at a young age.

572

573 


\section{S1 Figure. Illustration of part 3 of the survey}

Characterization of the common production systems. Similar pages were shown for the three other

animal categories.

578

579

580

581

582

583

584

585

586

587

588

589

590

591

592

593

594

595

\section{Calves raised for production of red-meat $(9 \&$ \& $):$}

Here we ask that you rate the 12 statements in relation to calves raised for production of red-meat (not veal). This category includes male and female beef calves, and in dairy systems mostly male dairy calves. The evaluation period is based on the lives of the calves from birth to 18 months of age (or until slaughter, if it occurs earlier). The evaluation should NOT include transportation to slaughter or the process of slaughter itself.

\section{Q170}

Before we start, please tell us a bit about the most common red-meat production systems in your country of residence/expertise. Please remember to rate the 12 statements that will later follow based on these common systems.

\section{BEEF calves raised for RED-MEAT \\ DAIRY calves raised for RED-MEAT}

\section{Access to pasture}

Access to dam during first months of life

Suckling from dam during the first months of life

Transportation during the first 6 months of life

Slaughter before 18 months of age $\nabla$ Yes (1 ... I don't know (4)

Yes (1 ... I don't know (4)

Yes (1 ... I don't know (4)

$\nabla$ Yes (1 ... I don't know (4)

Yes (1 ... I don't know (4) $\boldsymbol{\nabla}$ Yes (1 ... I don't know (4)

Yes (1 ... I don't know (4)

Yes (1 ... I don't know (4)

Yes (1 ... I don't know (4)

Yes (1 ... I don't know (4) 


\section{S2 Figure. Illustration of part 3 of the survey}

Please rate the likelihood of the statements below on a scale of 1 (very low) to 7 (very high). Notice that the statements are built in such a way that the higher the likelihood ratings are, the higher is the welfare-risk for the animal.

\section{calf raised for red-meat to:}

Receive inappropriate/inadequate diet (e.g. quantity of milk/feed, number of feeding bouts, quality of feed, digestibility etc.).

Have inadequate water supply (e.g. quantity, quality, accessibility, high competition over access to water).

Experience discomfort when resting (e.g. when lying down, standing up etc.).

Experience thermal discomfort (i.e. being too warm (e.g. heat load) or too cold).

Experience restricted movement (e.g. limited ability to move around freely,

e.g. being tied, kept in high stocking density).

Suffer from injuries (e.g. lameness, skin lesions etc.).

Suffer from disease.

Suffer from pain induced by management, handling, or surgical procedures.

Have limited opportunities to express normal, non-harmful, social behaviours (e.g. limited allo-grooming, limited social play etc.).

Have limited opportunities to express other normal behaviours (i.e. limited/restricted from opportunity to forage/graze).

Experience negative affective states (e.g. fear, distress, frustration or apathy; due to negative human-animal relationships, husbandry / management or the environment in which the animal is kept).

Have limited opportunities to experience positive emotions (e.g. limited opportunities to engage in rewarding activities).

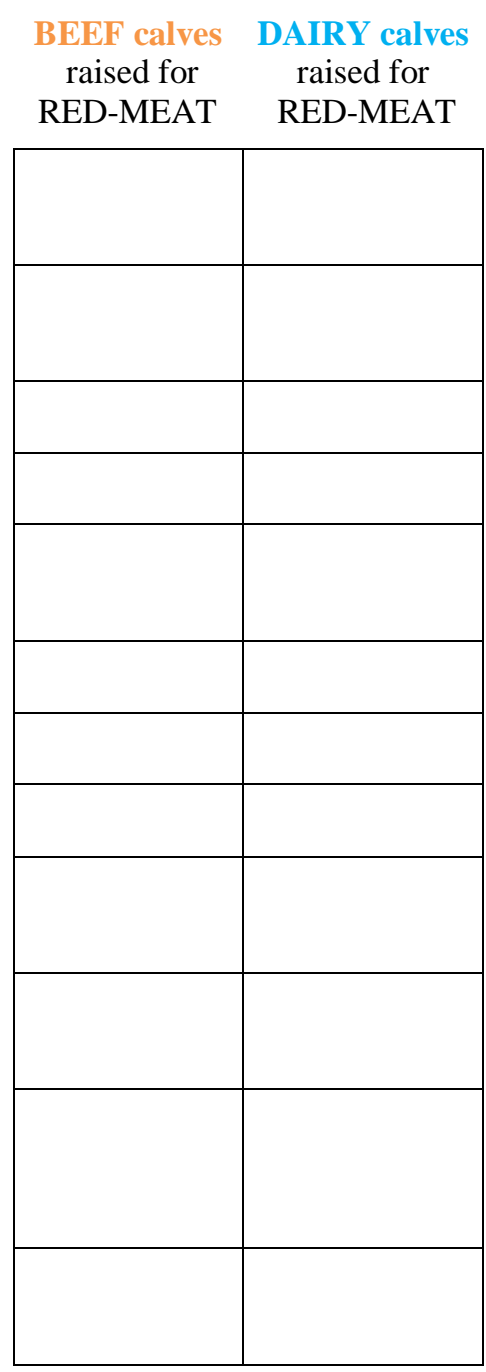

How confident were you to answer questions about calves raised for production of red-meat? ( 1 = low confidence, $5=$ high confidence $)$.

\begin{tabular}{l|ccccc|ccccc} 
& $\begin{array}{c}\text { BEEF calves } \\
\text { raised for } \\
\text { RED-MEAT }\end{array}$ & \multicolumn{2}{|c|}{$\begin{array}{c}\text { DAIIRY calves } \\
\text { raised for } \\
\text { RED-MEAT }\end{array}$} \\
\hline & 1 & 2 & 3 & 4 & 5 & 1 & 2 & 3 & 4 & 5 \\
Confidence rating & $\bigcirc$ & $\bigcirc$ & $\bigcirc$ & $\bigcirc$ & $\bigcirc$ & $\bigcirc$ & $\bigcirc$ & $\bigcirc$ & $\bigcirc$
\end{tabular}




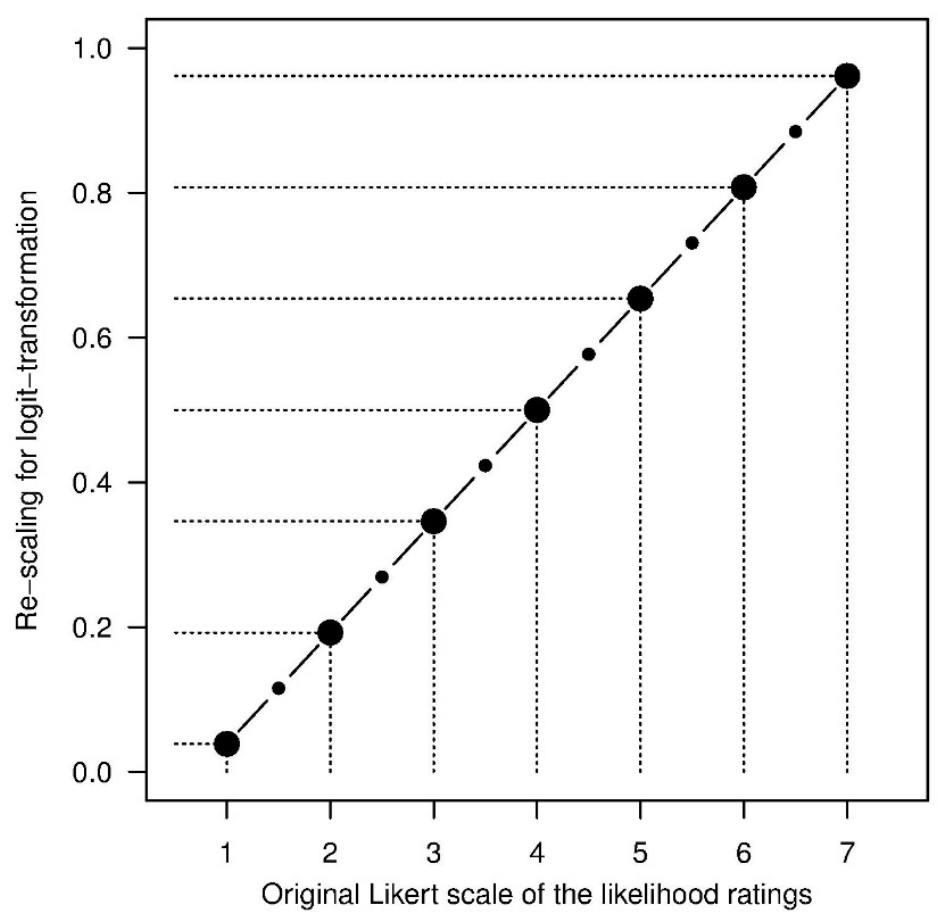

605

606

607

608

609

610

611

612

613

614

615

616

617

618

619 
621 in the space spanned by the $1^{\text {st }}$ and $2^{\text {nd }} \mathrm{PC}$ (beef origin in red and dairy origin in blue). The

622 directions of the twelve welfare statements is given in the top-inset. The relative contribution of the

62312 PCs to the overall variance is given in the bottom-inset. See Table 1 for the raw scores of the

624 original questions and S2 Table for the loadings of the original variables on the PCs.

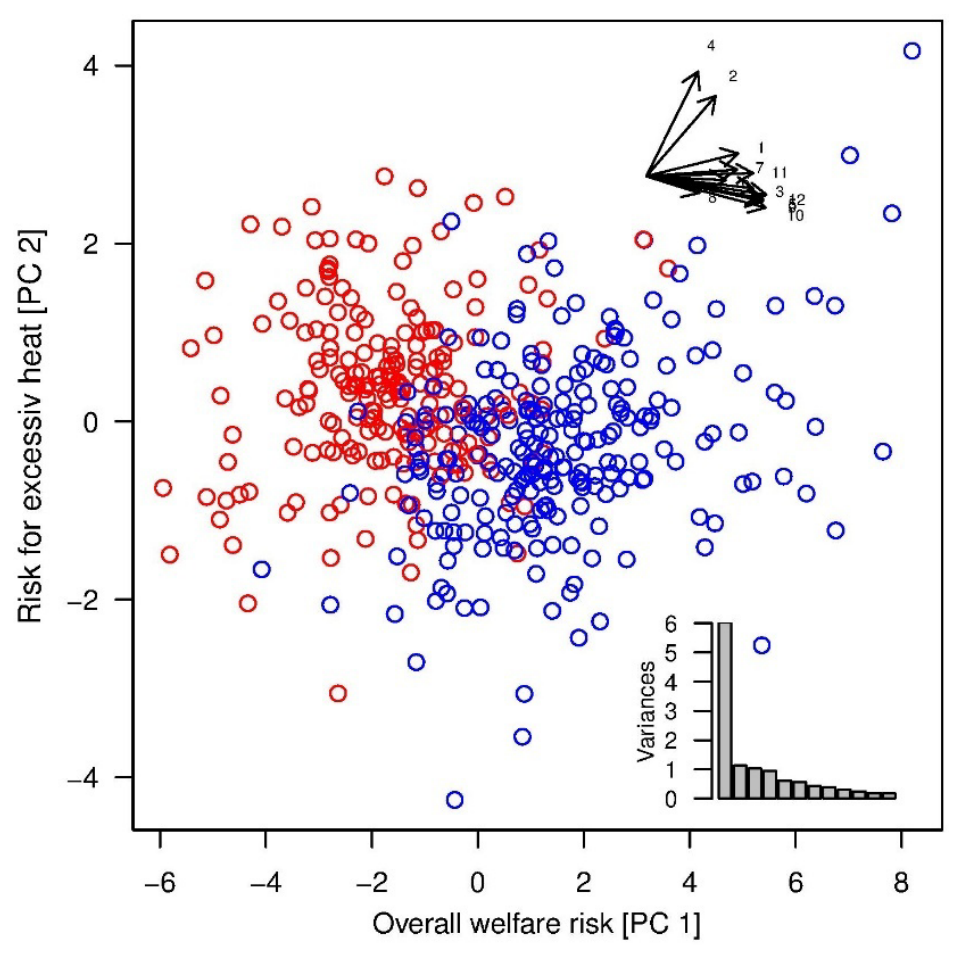


631 S5 Figure. Result of the PCAs for the information on the housing systems. In each diagram, all

632 observations are shown in the space spanned by the $1^{\text {st }}$ and $2^{\text {nd }} \mathrm{PC}$ (beef origin in red and dairy origin

633 in blue). Points are jittered to show the number of points with the same values on the PCs. The

634 directions of the original questions (S3 Table) is given in the top-inset. The relative contribution of

635 the PCs to the overall variance is given in the bottom-inset.

(a) Calves raised for red-meat

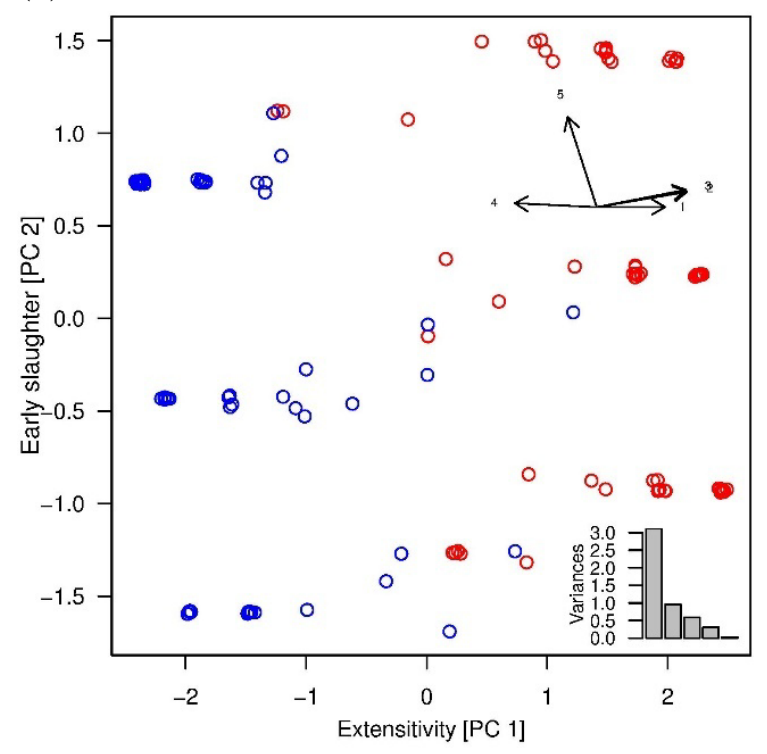

(c) Cows

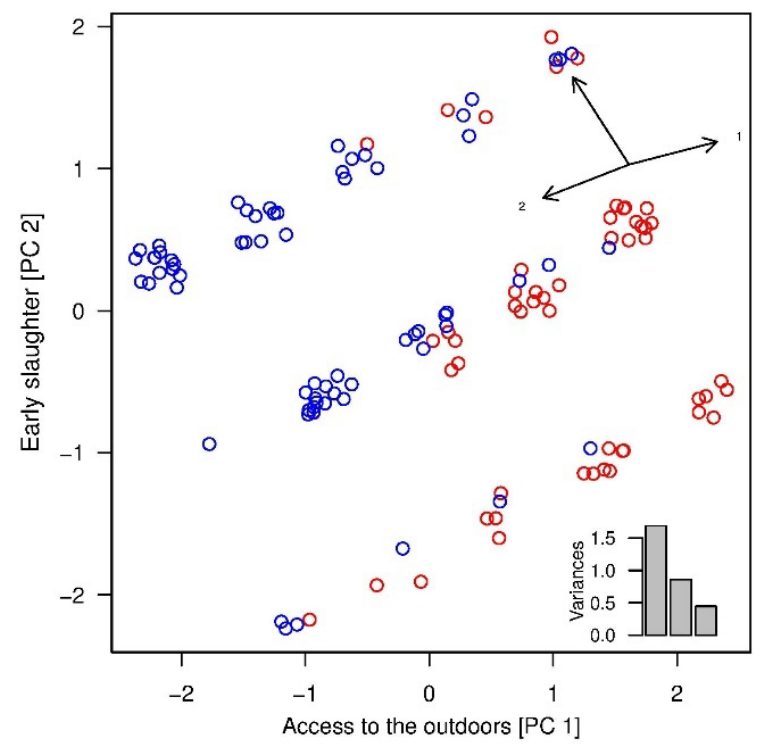

(b) Calves raised for replacement

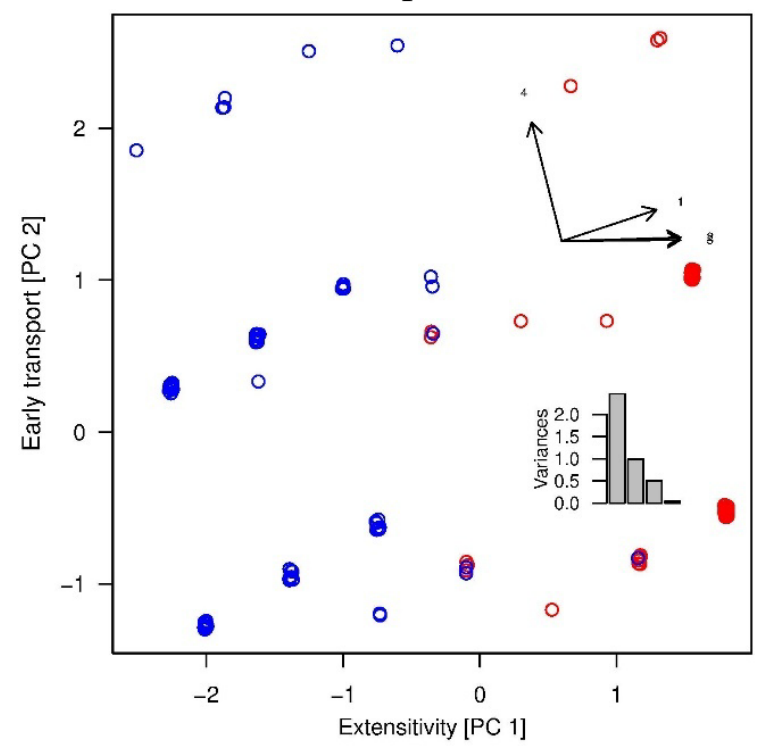

(d) Veal calves

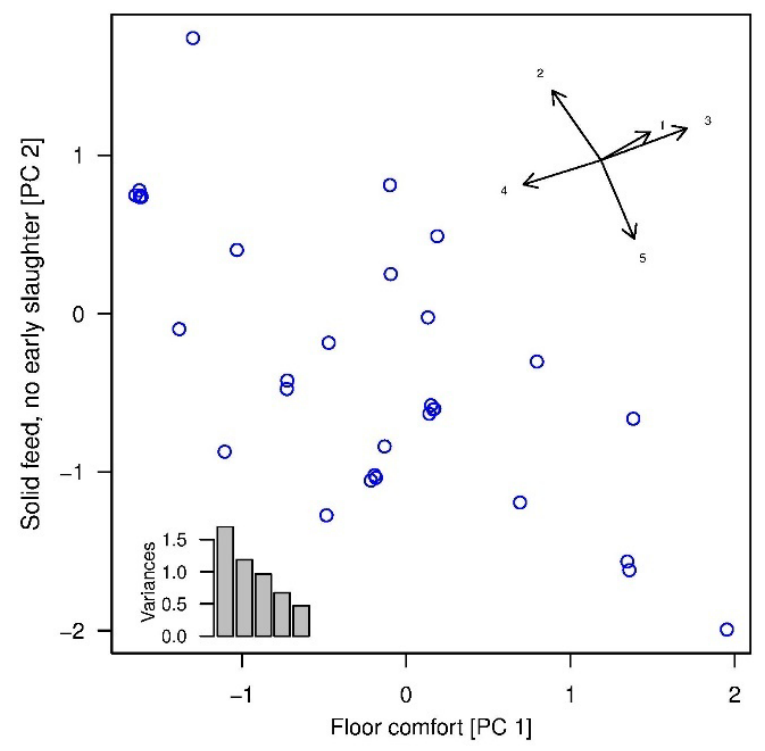


S1 Table - Expert characteristics.

639

640

\begin{tabular}{|c|c|c|c|c|}
\hline \multirow[t]{2}{*}{ Gender (number of experts) } & \multirow{2}{*}{$\begin{array}{l}\text { Female } \\
40\end{array}$} & \multicolumn{2}{|l|}{ Male } & \multirow[t]{2}{*}{641} \\
\hline & & 30 & & \\
\hline \multirow[t]{2}{*}{ Age (yr) } & $<30$ & 31-50 & $51-70$ & $71+$ \\
\hline & 1 & 32 & 34 & 3 \\
\hline \multirow[t]{2}{*}{ Reported expertise (number of experts) } & $\begin{array}{l}\text { Animal } \\
\text { Welfare } \\
\text { and/or } \\
\text { animal } \\
\text { behaviour }\end{array}$ & Veterinarian & Both & \\
\hline & 51 & 4 & 15 & \\
\hline \multirow{2}{*}{$\begin{array}{l}\text { Years of experience in Animal Welfare } \\
\text { research }\end{array}$} & $1-5$ & 6-10 & $11-15$ & $16+$ \\
\hline & 1 & 12 & 12 & 45 \\
\hline Total number of participants & 70 & & & \\
\hline Total number of countries of origin & 23 & & & \\
\hline
\end{tabular}


642 S2 Table. Loadings of the normalised values of the 12 welfare statements on the principle

643 components and cumulative variance explained by the principle components. (Components larger

644 than 0.3 are marked in bold).

645

646

\begin{tabular}{|c|c|c|c|c|}
\hline Cumulative variance & $\begin{array}{l}\text { PC1 } \\
0.503\end{array}$ & $\begin{array}{l}\text { PC2 } \\
0.596\end{array}$ & $\begin{array}{l}\text { PC3 } \\
0.681\end{array}$ & $\begin{array}{l}\text { PC4 } \\
0.760\end{array}$ \\
\hline Q1: Inappropriate / inadequate diet & 0.275 & 0.158 & 0.292 & 0.135 \\
\hline Q2: Inadequate water supply & 0.207 & 0.556 & 0.158 & 0.334 \\
\hline Q3: Discomfort when resting & 0.319 & -0.083 & -0.274 & 0.174 \\
\hline Q4: Thermal discomfort & 0.155 & 0.724 & -0.086 & -0.211 \\
\hline Q5: Restricted movement & 0.349 & -0.157 & -0.051 & 0.219 \\
\hline Q6: Injuries & 0.237 & -0.028 & -0.589 & -0.353 \\
\hline Q7: Disease & 0.271 & 0.046 & -0.214 & -0.432 \\
\hline Q8: Pain & 0.158 & -0.116 & 0.623 & -0.592 \\
\hline $\begin{array}{l}\text { Q9: Limited ability to Express social } \\
\text { behaviours }\end{array}$ & 0.349 & -0.172 & 0.063 & 0.239 \\
\hline $\begin{array}{l}\text { Q10: Limited ability to Express other } \\
\text { normal behaviours }\end{array}$ & 0.357 & -0.218 & 0.072 & 0.032 \\
\hline $\begin{array}{l}\text { Q11: Experience negative affective } \\
\text { states }\end{array}$ & 0.319 & 0.021 & 0.074 & -0.132 \\
\hline $\begin{array}{l}\text { Q12: Limited ability to Experience } \\
\text { positive emotions }\end{array}$ & 0.359 & -0.129 & 0.093 & 0.101 \\
\hline
\end{tabular}


647 S3 Table. Loadings of the questions on housing conditions of calves kept for the production of red meat, of calves kept as

648 replacement animals, of cows kept for dairy or meat production, and of veal calves on the principle components and cumulative

649 variance explained by the first two principle components each. (Components larger than 0.3 are marked in bold).

\begin{tabular}{|c|c|c|c|c|c|c|c|c|c|c|c|c|}
\hline \multirow[b]{3}{*}{ Cumulative variance } & \multicolumn{3}{|c|}{$\begin{array}{l}\text { Calves kept for the } \\
\text { production of red } \\
\text { meat }\end{array}$} & \multicolumn{3}{|c|}{$\begin{array}{l}\text { Calves kept as } \\
\text { replacement animals }\end{array}$} & \multicolumn{3}{|c|}{$\begin{array}{l}\text { Cows kept for dairy } \\
\text { or meat production }\end{array}$} & \multicolumn{3}{|c|}{ Veal calves } \\
\hline & & PC1 & PC2 & & PC1 & PC2 & & PC1 & $\mathrm{PC} 2$ & & PC1 & $\mathrm{PC} 2$ \\
\hline & & & & & & & & & & & & \\
\hline Access to pasture & Q1 & 0.407 & 0.002 & Q1 & 0.486 & 0.256 & Q1 & 0.652 & 0.237 & Q1 & 0.354 & 0.244 \\
\hline Access to dam during first months of life & Q2 & 0.536 & 0.164 & Q2 & 0.608 & 0.030 & & & & & & \\
\hline Suckling from dam during the first months of life & Q3 & 0.530 & 0.187 & Q3 & 0.608 & 0.010 & & & & & & \\
\hline $\begin{array}{l}\text { Provided with solid feed, in addition to milk/milk } \\
\text { replacer (from age of } 2 \mathrm{w} \text { ) }\end{array}$ & & & & & & & & & & Q2 & -0.350 & 0.601 \\
\hline Provided with bedding material (from age of $2 \mathrm{w}$ ) & & & & & & & & & & Q3 & 0.618 & 0.275 \\
\hline Slatted floor from the age of $8 \mathrm{w}$ onwards & & & & & & & & & & Q4 & -0.559 & -0.209 \\
\hline Indoor housing & & & & & & & Q2 & -0.635 & -0.348 & & & \\
\hline Transportation during first 6 mo of life & Q4 & -0.487 & 0.043 & Q4 & -0.154 & 0.966 & & & & & & \\
\hline Slaughtered before $8 \mathrm{mo}$ of age & & & & & & & & & & Q5 & 0.240 & -0.678 \\
\hline Slaughter before 18 mo of age & Q5 & -0.173 & 0.968 & & & & & & & & & \\
\hline Slaughter age below 6 y & & & & & & & Q3 & -0.414 & 0.907 & & & \\
\hline
\end{tabular}

